\title{
Molecular regulation of sink-source transition in rice leaf sheaths during the heading period
}

\author{
Huai-Ju Chen · Shu-Jen Wang
}

Received: 26 October 2007/Revised: 18 February 2008/Accepted: 26 February 2008/Published online: 11 March 2008

(C) Franciszek Górski Institute of Plant Physiology, Polish Academy of Sciences, Kraków 2008

\begin{abstract}
The upper leaf sheath of rice (Oryza sativa L.) serves as a temporary starch sink before heading, subsequently becoming a carbon source tissue to the growing panicle at the post-heading stage. The time of sink-source transition in upper leaf sheaths is highly correlated to the panicle exsertion. Here, we found that the expression profiles of starch synthesis genes such as ADP-glucose pyrophosphorylase large subunit 2, granule-bound starch synthase II, soluble starch synthase I, starch branching enzyme (SBE) I, SBEIII, and SBEIV were highly correlated with starch content changes during the heading period in the second leaf sheath below the flag leaf. In addition, the $\alpha$-amylase $2 A$ and $\beta$-amylase were considered as major genes that were in charge of starch degradation at the postheading period. Of the five sucrose transporter (OSSUT) genes, OSSUT1 and OSSUT4 appeared to play an important role in sucrose loading into the phloem of source leaf sheaths. Moreover, the microarray-based data implied that the dominant processes associated with functional leaf sheath transition from sink to source were carbohydrate metabolism and the translocation of the carbon and nitrogen sources and inorganic phosphate.
\end{abstract}

Keywords Oryza sativa . Leaf sheath . Oligonucleotide microarray · Sink-source transition . Starch

Communicated by H. Janska.

H.-J. Chen · S.-J. Wang ( $₫)$

Department of Agronomy, National Taiwan University,

1, Section 4, Roosevelt Rd, Taipei 106, Taiwan

e-mail: shujen@ntu.edu.tw

H.-J. Chen

e-mail: d92621103@ntu.edu.tw

\author{
Abbreviations \\ AGPase ADP-glucose pyrophosphorylase \\ DBE Debranching enzyme \\ GBSS Granule-bound starch synthase \\ SBE Starch branching enzyme \\ SSS Soluble starch synthase \\ SUT Sucrose transporter
}

\section{Introduction}

In cereal crops such as rice and wheat, a sufficient carbon source translocated to developing grains is an important factor in determining grain yield. There are two major carbon sources for grain filling: photoassimilates produced in mature leaves at the reproductive stage and carbohydrates pre-accumulated in stems (leaf sheaths and culms) before heading. Starch accumulation in stems peaks around the heading date and then decreases during grain development (Perez et al. 1971; Yoshida 1972). This process of starch changes in stems is defined as the sink-source transition. The carbohydrate accumulated in stems at the pre-heading period contributes around $30 \%$ of grain production, and levels of pre-stored carbohydrates are positively correlated to grain yield (Cock and Yoshida 1972; Ishikawa et al. 1993; Samonte et al. 2001). In addition, pre-storage carbohydrate in stems also serves as an alternative carbon buffer in unfavorable environments to compensate for insufficiencies of photosynthesis (Yoshida 1972; Blum et al. 1994). Under deficient water conditions, carbohydrate translocation efficiency from stems to grains increases, which would result in a shortened grain-filling period (Yang et al. 2004).

Improving the sink and source functions of stems by controlling starch metabolism would be a powerful 
approach for enhancing cereal crop production. There are at least five groups of enzymes involved in the starch synthetic pathway (reviewed by Tetlow et al. 2004). ADPglucose pyrophosphorylase (AGPase) is the key enzyme synthesizing ADP-glucose, which provides the glucose substrate to elongate amylose and amylopectin chains. It consists of two large and two small subunits to form a heterotetramer. Granule-bound starch synthase (GBSS) is responsible for elongation of the amylose molecules, and two GBSS isoforms, GBSSI and GBSSII, have been identified in plants. The soluble starch synthase (SSS) localizes in the plastidic stroma and contributes to the elongation of the amylopectin branching chains. At least four kinds of SSS isoforms have been found in rice: SSSI, SSSII, SSSIII, and SSSIV; each SSS isoform is encoded by a small multigene family (Hirose and Terao 2004). The other two enzyme groups are starch branching enzymes (SBE) and debranching enzymes (DBE). They regulate the formation and degradation, respectively, of $\alpha-1,6$ glucan branch chains of amylopectin. Numerous distinct classes of SBE isoforms, such as SBEI, SBEIII, and SBEIV, have been identified in rice (Nakamura et al. 1992; Mizuno et al. 1993).

In rice plants, the leaf sheaths of higher-position leaves on stems have been identified as the major temporary storage organs before heading. According to Watanabe et al. (1997), the changes in SBE activity are highly correlated with leaf sheath starch content during the heading period, and the activity patterns of GBSS and SSS also track the changes in starch levels. Although in previous studies, expression of some starch metabolism enzymes and genes in upper leaf sheaths has been observed during the heading period (Hirose et al. 1999, 2006; Takahashi et al. 2005), little was known about the regulatory mechanism of starch metabolism in leaf sheaths during the transition from sink to source as it relates to the heading period. Because most starch synthesis-related enzymes are encoded by multiple gene families, elucidation at the gene level of the contributions of each starch synthesis enzyme would enhance understanding of starch biosynthetic regulation in leaf sheaths during the sink-source transition.

In this study, we attempted to clarify the molecular mechanism of the sink-to-source transition in rice leaf sheaths. To achieve this, we determined the relationship during the heading period between starch content and expression of multiple genes encoding each starch synthesis-related enzyme in leaf sheaths. Subsequently, the expressions of starch degradation enzyme and sucrose transporter genes were also analyzed during the heading period. In addition, a microarray approach was used to analyze comparative whole rice genomic expression in sink and source leaf sheaths, with results suggesting that activation of nutrient translocation was the key physiological function in leaf sheaths at the post-heading stage.

\section{Materials and methods}

Plant materials

Rice (Oryza sativa L. cv. Tainung 67) seeds were sterilized in $1 \%(\mathrm{v} / \mathrm{v})$ sodium hypochlorite with Tween 20 for $15 \mathrm{~min}$ and subsequently washed three times with distilled $\mathrm{H}_{2} \mathrm{O}$. Seeds were then germinated at $37^{\circ} \mathrm{C}$ in the dark for 2 days and then moved to the phytotron for seedling growth with half-strength Kimura B nutrient solution (Chu and Lee 1989) at $30 / 25^{\circ} \mathrm{C}$ under natural daylight until the three-leaf-stage. Seedlings $(n=15 /$ pot $)$ were transplanted into pots $(62 \mathrm{~cm}$ in length, $36 \mathrm{~cm}$ in width, and $24 \mathrm{~cm}$ in height) containing soil. Each pot was placed in the screenhouse in the experimental field of National Taiwan University at Taipei, Taiwan. Leaf samples for starch content and gene expression analyses were harvested during the heading period. The preheading stages were defined by the inter-collar length, which is the distance between the collar of the flag leaf and the first leaf below the flag leaf (-1 leaf). Inter-collar lengths of $-4 \pm 1,0,4 \pm 1$, and $9 \pm 1 \mathrm{~cm}$ were, respectively, associated with $20,15,10$, and 5 days before heading. All samples were harvested around 13:00 to 15:00 hours, and leaf samples were divided into leaf blades and sheaths before being frozen in liquid nitrogen. For gene expression analyses by real-time RT-PCR and oligonucleotide microarray, the leaf sheath samples of the second leaf below the flag leaf ( -2 leaf) were harvested.

\section{Starch content analysis}

For starch content determination in different leaves, the upper leaves including the first, second, and third leaves below the flag leaf (the -1 to -3 leaves) on the main stems were collected from 20 days before to 20 days after heading. For starch extraction, leaf sheath samples $(0.5 \mathrm{~g})$ were ground with liquid nitrogen, and the sample powder was extracted twice with $5 \mathrm{ml}$ of $80 \%$ (v/v) ethanol at $80^{\circ} \mathrm{C}$ for $5 \mathrm{~min}$. After centrifugation at $2,000 \times g$ for $5 \mathrm{~min}$, samples were washed twice with $\mathrm{H}_{2} \mathrm{O}$ at room temperature. Then, each sample was resuspended with $3 \mathrm{ml} \mathrm{H}_{2} \mathrm{O}$ and boiled for $2 \mathrm{~h}$. Amyloglucosidase and pullulanase were then used to digest the starch samples at $55^{\circ} \mathrm{C}$ for $1.5 \mathrm{~h}$ before boiling for $5 \mathrm{~min}$ to stop the enzyme activity. Starch content was determined using the procedure described by Keppler and Decker (1974). 


\section{RNA extraction}

A 100-mg sample of each of the leaf sheaths was homogenized in $1 \mathrm{ml}$ Trizol reagent (Invitrogen, Carlsbad, CA, USA) before centrifugation at $10,000 \times g$. The supernatant was treated with $0.2 \mathrm{ml}$ chloroform and shaken for $15 \mathrm{~s}$ before incubation at room temperature for $3 \mathrm{~min}$. The upper layer of the solution was transferred to a new tube after centrifugation at $12,000 \times g$ for $15 \mathrm{~min}$ at $4^{\circ} \mathrm{C}$. RNA was precipitated with $0.5 \mathrm{ml}$ isopropanol and incubated for $10 \mathrm{~min}$ at room temperature. After centrifugation, the pellet was dissolved completely in $0.5 \mathrm{ml} \mathrm{H}_{2} \mathrm{O}$.

Quantitative real-time reverse transcriptase (RT)-PCR

Total RNA (200 ng) was used as the template for quantitative real-time RT-PCR analyses with Brilliant SYBR Green QRT-PCR Master Mix (Stratagene, La Jolla, CA, USA), and the PCR reactions were performed in using a Multiplex 3000P Real-Time PCR System (Stratagene). The gene-specific primers for RT-PCR were listed in Table 1. RT-PCR was carried out as follows: $50^{\circ} \mathrm{C}$ for $30 \mathrm{~min} ; 95^{\circ} \mathrm{C}$ for $10 \mathrm{~min}$; 40 cycles of $95^{\circ} \mathrm{C}$ for $1 \mathrm{~min}$; annealing temperature for $1 \mathrm{~min}$; and $72^{\circ} \mathrm{C}$ for $1 \mathrm{~min}$. To accurately quantify relative expression levels of the genes, the $\mathrm{C}_{\mathrm{T}}$ value for each identified gene was normalized to the $C_{T}$ value of Actin. For all real-time RT-PCR analyses, three independent experiments were carried out, and the data are presented as mean $\pm \mathrm{SE}$.

\section{Microarray analysis}

Total RNA isolated from the -2 leaf sheaths harvested 10 days before heading was the sink sample; RNA from the -2 leaf sheaths harvested 5 days after headings were considered source RNA samples. The RNA samples $(1 \mu \mathrm{g}$ each) were pre-treated with DNase I, and then the sink RNA sample was labeled with $\mathrm{Cy} 3$ and the source RNA sample with Cy5. cDNA synthesis was achieved using the MessageAmp aRNA kit (Ambion, Austin, TX, USA). Hybridization was performed on the Rice Oligo Microarray (Agilent Technologies, Palo Alto, CA, USA) containing around 20,000 oligonucleotides and following the manufacturer's Oligonucleotide Microarray Hybridization protocol. For data analysis, we used a GenePix4000B scanner and GenePix Pro 5.1 software. Gene expression differences between the sink and source samples were determined as the ratio of source-to-sink sample expression (ratio of the Cy5 intensity to Cy3 intensity; Cy5/Cy3). When $\mathrm{Cy} 5 / \mathrm{Cy} 3>1$, the gene was considered to be upregulated in the source samples; Cy $5 / \mathrm{Cy} 3<1$ indicated down-regulated gene expression. On the microarray, there were several housekeeping genes such as Actin and
Glucose-6-phosphate dehydrogenase (G6PDHase). The results showed that the $\mathrm{Cy} 5 / \mathrm{Cy} 3$ ratio among the 16 Actin genes ranges from 0.6 to 1.9 ; those among the five G6PDHase genes from 0.7 to 1.3 . After data analysis, only the genes with a threefold or greater difference in expression between the sink and the source samples (Cy5/ Cy3 $>3.0$ or $<0.3$ ) were selected and further classified based on their putative functions. The microarray analysis was performed once. Expression profiling of several genes selected from the microarray data was further verified by three replicate quantitative real-time RT-PCR analyses in the -2 leaf sheaths harvested during the heading period.

\section{Results}

Changes in starch content in rice upper-leaf sheaths during the sink-source transition

Starch content in the rice leaf sheaths of upper leaves was examined from 20 days before to 20 days after heading. During this period, starch content changed significantly in the -2 leaf sheaths. Starch accumulation in the -2 leaf sheaths rapidly increased before the panicle exsertion and peaked at the date of heading, followed by an immediate decrease (Fig. 1). Changes in starch content were also observed in the -1 and -3 leaf sheaths, but they were not as significant as those identified in the -2 leaf sheaths (Fig. 1). The starch content of the -3 leaf sheaths was less than that of the -1 and -2 leaf sheaths during the heading period (Fig. 1).

To identify further the relationship between panicle exsertion and starch degradation in the -2 leaf sheaths, the young panicles were removed from flag leaf sheaths 5 days before the predicted heading date. As shown in Fig. 2, starch degradation was retarded in the panicle-free plants. Around 15 days after panicle removal, the starch content peaked, and starch levels in the -2 leaf sheaths of the panicle-free plants were higher than those of control samples throughout the period of starch degradation (Fig. 2). This result indicated that the sink-source transition of the -2 leaf sheath was highly related to panicle exsertion.

Correlation of starch contents and starch metabolism-related gene expression in leaf sheaths during the sink-source transition

To identify the key starch synthesis genes involved in determining the starch content in the leaf sheaths during the sink-source transition, the -2 leaf sheath samples were harvested from 20 days before to 20 days after heading. Each leaf sheath was divided lengthwise into two equal 
Table 1 Primer pairs for real-time RT-PCR

\begin{tabular}{|c|c|c|c|c|}
\hline Gene & $\begin{array}{l}\text { Accession } \\
\text { number }\end{array}$ & Forward primer $\left(5^{\prime} \rightarrow 3^{\prime}\right)$ & Reverse primer $\left(5^{\prime} \rightarrow 3^{\prime}\right)$ & $\begin{array}{l}\text { Amplicon } \\
\text { size (bp) }\end{array}$ \\
\hline$A G P-L 1$ & U66041 & CGGGACCGTCATATAAAAGCA & TCССАТТССАAАACAAАCCA & 242 \\
\hline$A G P-L 2$ & D50317 & TCTTGAGGACTATTACAAGCA & GTCCATAGTCAGATGCTCGA & 170 \\
\hline$A G P-S 1$ & AY028315 & AGAATGCTCGTATTGGAGAAAATG & GGCAGCATGGAATAAACCAC & 249 \\
\hline$A G P-S 2$ & J04960 & TGTCCAAGAAGCTGCAAGAGA & TCCCAAAACATCTGAAAAGCA & 270 \\
\hline GBSSI & AF515482 & GCGAAGAACTGGGAGAATG & CACTACAACAAACAAACCACTG & 200 \\
\hline GBSSII & AY069940 & AACTGCATGGCTCAAGACCT & ACAGGCAAATGCATGCCATC & 350 \\
\hline SSSI & D38221 & CGACATACAGGGAACACAAG & GAAAGACAGGAAGATTGAGGG & 196 \\
\hline SSSII-1 & AF383878 & TGCCCGTTCTGTTCTTGTC & CGTCTGGAACTTCATCAAGA & 195 \\
\hline SSSII-2 & AF395537 & TGCGAAGCAAAATGGAGAG & TCTTGTCCAGTGCAGCCTT & 148 \\
\hline SSSII-3 & AF419099 & CTCTCTTCCGTCACCGTCAG & GGAGCACTCTCAACAACTTTT & 205 \\
\hline SSSIII & AF432915 & GCTGCAAACTCCATATACCC & TTCAACCAAGAAGTCCTCAA & 152 \\
\hline SSSIV-1 & AY100470 & AGCTTCACAGTACGAAAACC & СААТСССАССТСТССТААСС & 548 \\
\hline SSSIV-2 & AY100471 & AAGCCTGAGGCCTGGAAAC & TCTCACTAAACCGCCAGAG & 146 \\
\hline SBEI & D11082 & GCCCTAACTCATTCAAAGTCC & TCTCCCCACTTGTTGCTTC & 153 \\
\hline SBEIII & D16201 & TGAGAACACCAAGAGGCAG & CGCAAAGCACAAAAGCAAG & 150 \\
\hline$S B E I V$ & E14723 & TTGAGGAGGAGGAAGAGATT & TGGAGCCTGCACAGCAAAC & 599 \\
\hline$D B E$ & D50602 & AAGTGACATTGAGCAAAGGG & CGTGTGGACAGACATTGAAG & 164 \\
\hline Actin & AB047313 & GAATGCTAAGCCAAGAGGAG & AATCACAAGTGAGAACCACAG & 170 \\
\hline$\beta$-amylase & AK068968 & AACCCTCACAATCCCGTTC & TCAATCAAACAGAGACAGACAG & 222 \\
\hline$\alpha$-amylase $1 A$ & X16509 & CACGATGACGAGACTCTCA & AATTGCATCCGTAATTCGGA & 77 \\
\hline$\alpha$-amylase $2 A$ & M74177 & GCCGATCATCGCACCT & ACGTACCTTTGAAGGTAG & 114 \\
\hline$\alpha$-amylase $3 E$ & M59352 & GCTATGAATCATGCAATTTT & AAACGAACAGTAGCTAGTTA & 168 \\
\hline$\beta$-D-glucan exohydrolase & AK065044 & AAGGCAGAGGAGAGGGAAAG & GCACACACATACATACAGCAC & 211 \\
\hline Sucrose synthase & NM184941 & AGGCTGAGACTCTGAAAGAG & AGAGCACCAACCACACACCA & 220 \\
\hline $\begin{array}{c}\text { Putative sorbitol } \\
\text { transporter }\end{array}$ & AK073216 & GACACCGTCAAACTCTTCG & TAGTAGCCCTCACTGGTCAC & 179 \\
\hline Ammonium transporter & AK107601 & ATGCTTTTGCCGCTCTCTC & TTCCСACСТTCACACCACAC & 137 \\
\hline Phosphate transporter & AK101380 & СТCСCTCCTCGTCATACTTC & GCAACTCAAGATTCGCACC & 249 \\
\hline OsSUT 1 & D87819 & CTGTGATTTTCCTGTCCCTG & AACACTGCTAGTGGACCAGT & 136 \\
\hline OsSUT 2 & AB091672 & AGGAGGAGAGGTCACCGATAA & CCAACATCCAATGTACAACAGCA & 240 \\
\hline OsSUT 3 & AB071809 & GCCCAAGGTCTCCGTCC & TGCTATAGTACCCGCTCTAA & 137 \\
\hline OsSUT 4 & AB091673 & TTTGGCTGAGCAGAACACCA & ATGTCATTCGGGCAGAGCTT & 249 \\
\hline OSSUT 5 & AB091674 & CTAGTGCGAAACTCCATCAAA & AAAATATTTGGGTTTCCTGAGAT & 250 \\
\hline
\end{tabular}

The nucleotide sequences used for primer designing were presented by their accession numbers in GenBank

sections for quantitative determination of starch content and of starch synthesis-related gene expression, respectively. Correlations between gene expression and starch content were calculated. In the gene expression analyses, the 17 individual genes encoding the five groups of starch synthesis enzymes-AGPase, GBSS, SSS, SBE, and DBE-were examined by quantitative real-time RT-PCR with the gene-specific primers (Table 1). Expression of GBSSI and SSSII-3 was too low to be detected; for the other genes, the correlation coefficients between the mRNA level of each gene and the starch content during the heading period were shown in Table 2 . The data indicated that the transcript accumulations of AGP-L2, GBSSII, SSSI, SBEI, $S B E I I I$, and SBEIV were highly correlated with changes in starch content in the -2 leaf sheaths during the sink-source transition.

Expressions of $\alpha$-amylase, $\beta$-amylase and OsSUT genes in leaf sheaths during the sink-source transition

The expression of the $\alpha$-amylase isogenes, $\alpha$-amylase $1 A$, $2 A$, and $3 E$, were identified in the -2 leaf sheaths during the heading periods. The data showed that there are no significantly different expressions of $\alpha$-amylase $1 A$ and $3 E$ 


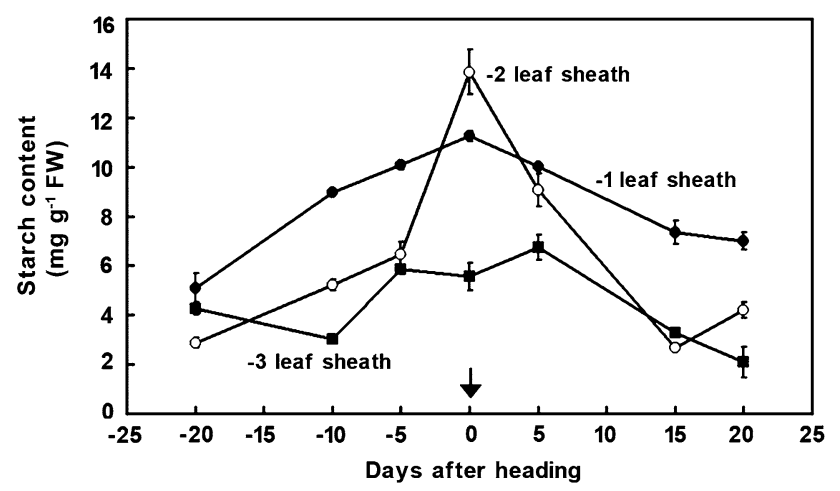

Fig. 1 Changes of starch contents in rice upper leaf sheaths during the heading period. Starch content changes in $-1,-2$ and -3 leaf sheaths. Starch contents in the -1 (filled circle), -2 (open circle), -3 (filled square) leaf sheaths were determined from 20 days before to 20 days after heading (sampling time: $-20,-10,-5,0,5,15,20$ days after heading). Standard errors $(n=3)$ are indicated with vertical bars. The arrow indicates the day of heading

between sink and source leaf sheath tissues (Fig. 3a, c). On the other hand, the expression of $\alpha$-amylase $2 A$ and $\beta$-amylase in the -2 leaf sheaths were about twofold enhanced after panicle exsertion (Fig. 3b, d). The expression patterns of OSSUT1, 2, 3, 4, and 5 were investigated in the -2 leaf sheaths during the heading periods. Real-time RT-PCR results showed that expression of OSSUT1 and 4 was enhanced after heading (Fig. 4a, c); however, OSSUT2 was steadily expressed during the heading period (Fig. $4 \mathrm{~b}$ ). On the other hand, transcript levels of OSSUT3 and OSSUT5 were very low in leaf sheaths (data not shown).

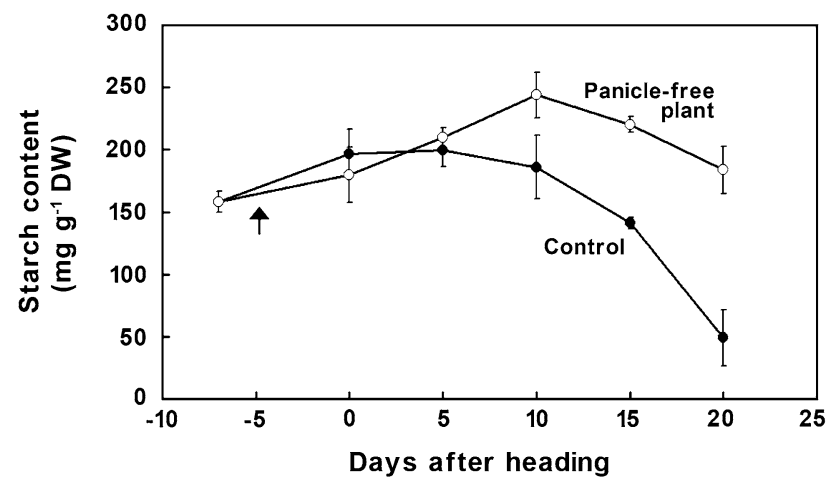

Fig. 2 Changes in starch metabolism patterns of leaf sheaths of rice plants with and without panicles. Starch content in -2 leaf sheaths of the control (filled circle) and panicle-free rice plants (open circle) were determined from 7 days before heading to 20 days after heading. Standard errors $(n=3)$ are indicated with vertical bars. The arrow indicates the time of the young panicles removed from rice plants
Microarray-based comparative analysis of gene expression in the sink and source leaf sheaths

The analyses of whole-genome expression in the -2 leaf sheaths at the pre-heading (sink) and post-heading (source) stages were assessed using a microarray approach. In total, 115 genes showed at least a threefold increase in expression, and 108 genes showed a threefold or greater decrease in expression in the source leaf sheaths; these genes were classified according their putative functions, such as carbohydrate metabolism, glycosylated modification, molecule transport, hormone synthesis, developmental regulation, and signaling and transcriptional regulation (Fig. 5).

Expression of the genes listed in Fig. 5 was further verified using real-time RT-PCR in the -2 leaf sheath samples harvested from 14 days before to 14 days after heading. The expression profiling of two selected carbohydrate metabolism- and three molecule transport-related genes was shown in Figs. 6 and 7, respectively. The results demonstrated that the expression of sucrose synthase genes was correlated with the pattern of starch changes (Fig. 6a). The transcript levels of $\beta$-D-glucan exohydrolase peaked at 7 days before heading and decreased subsequently (Fig. 6b). Transcript levels of putative sorbitol transporter, ammonium transporter, and phosphate transporter in leaf sheaths at the post-heading stage were higher than those at the pre-heading stage (Fig. 7). More specifically, transcript levels of ammonium transporter at 14 days after heading were increased 15-fold compared to levels at 14 days before heading (Fig. 7b).

\section{Discussion}

The temporary sink capacity and the source ability of upper leaf sheaths are important factors in determining rice yield (Cock and Yoshida 1972; Dingkuhn et al. 1991; Samonte et al. 2001). Our findings demonstrated that starch accumulation prior to rice heading and its degradation at the grain filling stage occurred in all of the $-1,-2$ and -3 leaf sheaths; however, the trend of sink-source transition was more significant in the mesophyll cells of the -2 leaf sheaths than in the other two leaf sheaths (Fig. 1). This result was agreed with the previous report published by Watanabe et al. (1997) and Hirose et al. (1999). On the other hand, the phenomenon of sink-source transition did not manifest in the flag leaf sheaths until the end of sampling period (data not shown). These results indicated that the -2 leaf sheath within the upper leaves functioned as the major temporary storage tissue before heading and then became a source tissue during the grain-filling period. The analysis of leaf sheath length demonstrated that the -2 leaf 
Table 2 Relationships between starch contents and the transcript levels of starch synthesis genes in the -2 leaf sheaths during the heading period

\begin{tabular}{|c|c|c|c|c|c|}
\hline \multicolumn{2}{|c|}{ ADP-glucose pyrophosphorylase } & \multicolumn{2}{|c|}{ Starch synthase } & \multicolumn{2}{|c|}{ Branching enzyme and debranching enzyme } \\
\hline Gene & $r^{\mathrm{a}}$ & Gene & $r^{\mathrm{a}}$ & Gene & $r^{\mathrm{a}}$ \\
\hline$A G P-L 1$ & -0.27 & GBSSII & $0.88 * *$ & $S B E I$ & $0.84 * *$ \\
\hline$A G P-L 2$ & $0.88 * *$ & SSSI & $0.69 *$ & SBEIII & $0.86^{* *}$ \\
\hline$A G P-S 1$ & 0.53 & $S S S I I-1$ & 0.23 & SBEIV & $0.81 * *$ \\
\hline \multirow[t]{4}{*}{$A G P-S 2$} & 0.44 & SSSII-2 & 0.52 & $D B E$ & 0.06 \\
\hline & & SSSIII & 0.34 & & \\
\hline & & $S S S I V-1$ & -0.06 & & \\
\hline & & $S S S I V-2$ & -0.44 & & \\
\hline
\end{tabular}

The leaf sheath samples were collected from 20 days before to 20 days after heading (sampling time: $-20,-15,-10,-5,0,10,15$ and 20 days after heading). The transcript levels of genes were determined by real-time RT-PCR. Following, the correlations of gene expressions and starch contents were analyzed

${ }^{a} r$ is the correlation coefficient of gene transcript level and starch content

$*$ and ** indicated significant correlation at the $P<0.05$ and $P<0.01$, respectively

sheaths were elongated completely by the first sampling day, 20 days before heading; therefore, the mature -2 leaf sheaths could serve as the storage sinks. However, the -1 leaf sheaths were still growing at 20 days before heading, indicating that the -1 leaf sheaths were at the growing sink stage (data not shown). In addition, differential starch content with position in a leaf sheath was observed by Ishimaru et al. (2004). In our study, it was also found the lower half part of -2 leaf sheath is the major starch storage tissue (data not shown).

The decrease in starch content in different upper leaf sheaths occurred almost simultaneously with the heading date, suggesting cross-talk between the mechanisms of panicle exsertion and starch metabolism in upper leaf sheaths. This hypothesis was supported by the delay in starch degradation in the -2 leaf sheaths of panicle-free plants (Fig. 2). Our results indicated that the sink demand of panicles played a role in regulating the source activity of the upper leaf sheaths. The effect of panicle removal on retarding the decrease of photosynthesis in flag leaf has been observed during the reproductive stage and attributed to a delay in flag leaf senescence (Nakano et al. 1995).

Based on the results of the assay of starch synthesis enzyme activity, SBE working with GBSS and SSS was considered the key enzyme in control of starch synthesis in leaf sheaths (Watanabe et al. 1997). To further clarify the molecular mechanism of starch metabolism in rice leaf sheaths during the sink-source transition, we examined the comprehensive expression of 17 genes encoding distinct isoforms of each AGPase, GBSS, SSS, SBE, and DBE in the -2 leaf sheaths. The result showed that the expression of all three $S B E$ isogenes, $S B E I, I I I$, and $I V$, was highly and
Fig. 3 Expressions of $\alpha$ amylase and $\beta$-amylase genes in leaf sheaths during the sinksource transition. The rice -2 leaf sheath samples were harvested at $-14,-7,0,7$ and 14 days after heading. The $\alpha$-amylase and $\beta$-amylase gene expressions were detected by real-time RT-PCR. Standard errors $(n=3)$ are indicated with vertical bars. Arrows indicate the day of heading

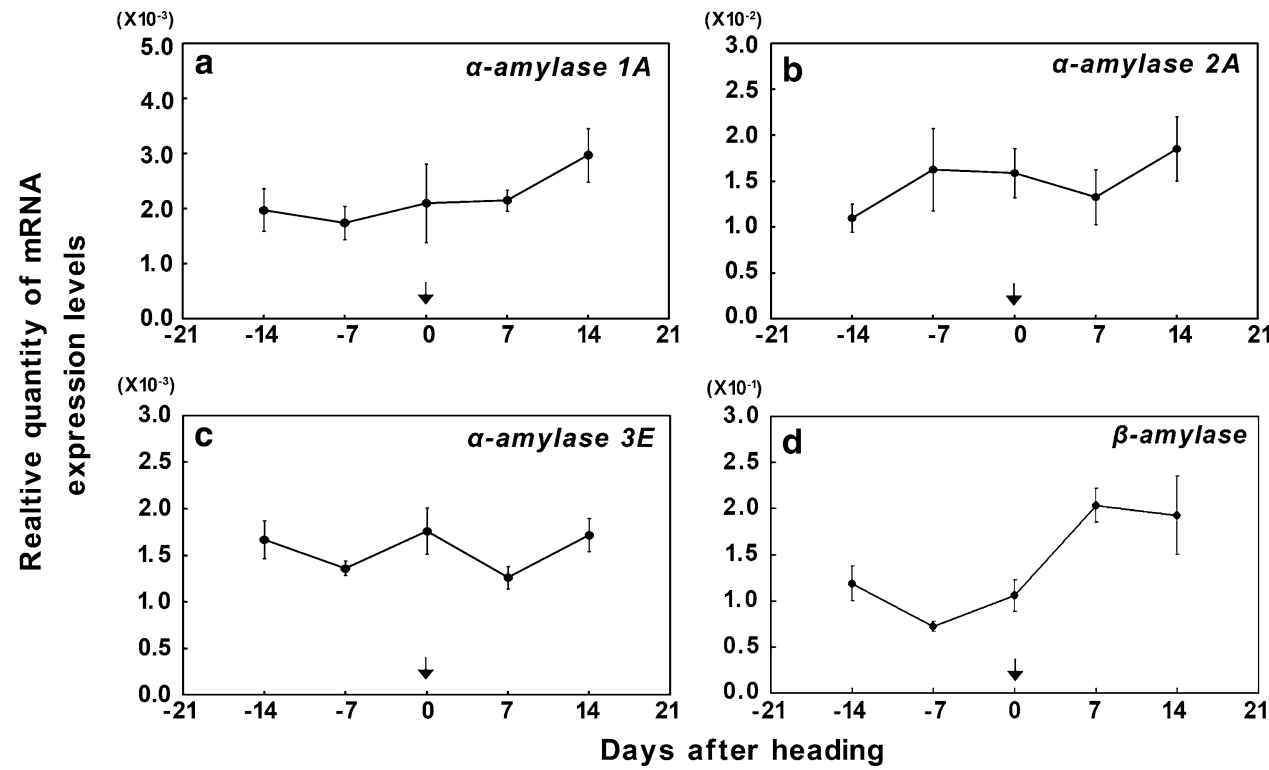



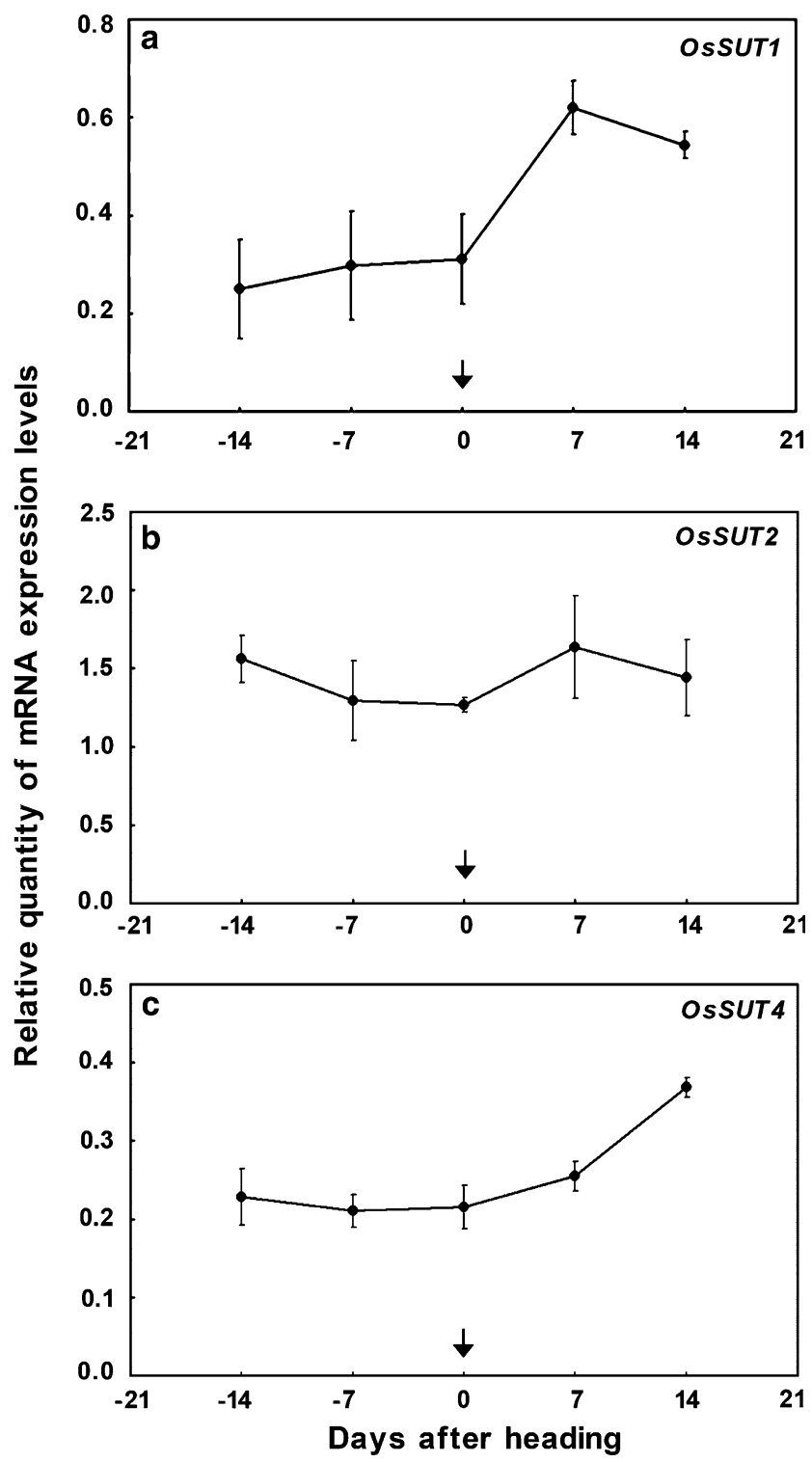

Fig. 4 Expression profiling of the OSSUT family genes in the -2 leaf sheaths during the heading period. The rice leaf sheath samples were harvested at $-14,-7,0,7$ and 14 days after heading. The OSSUT1, 2 and 4 gene expressions were detected by real-time RT-PCR. Standard errors $(n=3)$ are indicated with vertical bars. Arrows indicate the day of heading

positively correlated with starch levels (Table 2 ). In addition, expression of AGP-L2, GBSSII, and SSSI was also highly associated with changes in starch content during the sink-source transition (Table 2). In filling rice seeds, starch synthesis genes also present various expression patterns (Hirose and Terao 2004; Dian et al. 2005; Ohdan et al. 2005). Aforementioned phenomenon suggested that the genes involved in starch synthetic pathway may be regulated by different mechanisms during plant growth and development. There are several studies that provided the basis supporting the hypothesis. For examples, some of the reports indicated that sugar content was an important factor to control the starch accumulation mediated to regulate the expressions of starch synthesis-related genes; however, they also showed the sugar effect was not functioned on all of the genes involved in starch biosynthesis (Sokolov et al. 1998; Déjardin et al. 1999; Dian et al. 2005; Akihiro et al. 2005). In addition, Akihiro et al. (2005) reported that ABA could increase the transcript levels of $A G P-L 3, A G P-S 1$, and $A G P-S 2$, but it could not regulate $A G P-L 1, A G P-L 2$, and $A G P-L A$ expressions.

Perez et al. (1971) and Ishimaru et al. (2004) have reported that the activity of $\alpha$-amylase in rice culms and leaf sheaths would be increased during heading period. In $\alpha$-amylase gene family of rice, $\alpha$-amylase $1 A, 2 A, 3 D$ and $3 E$ were considered as the major isogenes expressed in leaf tissues (Thomas and Rodriguez 1994). However, the previous study showed that $\alpha$-amylase $3 D$ was not the dominant gene in charge of starch degradation in leaf sheaths at post-heading period (Takahashi et al. 2005). In our study, the expression patterns of $\alpha$-amylase1A, $2 A$, and $3 E$ in -2 leaf sheaths during heading period were analyzed. As shown in Fig. 3b, the transcript level of $\alpha$-amylase $2 A$ was increased after heading, and it was suggested that $\alpha$-amylase $2 A$ expression was important for starch degradation in leaf sheaths after panicle exsertion.

In Arabidopsis leaves, the starch granule hydrolyzed by $\beta$-amylase to derive maltose was indicated as the dominant starch degradation pathway in chloroplasts (Smith et al. 2005). This study showed that $\beta$-amylase, highly expressed in the rice leaf sheaths coincident with the decrease in starch content at the post-heading stage, could be the enzyme potentially responsible for hydrolyzing the starch in leaf sheath tissues (Fig. 3). In general, $\alpha$-amylase was the dominant enzyme for starch breakdown in germinating seeds, and the metabolic regulation of $\alpha$-amylase has also been well established (Karrer and Rodriguez 1992). The data presented here suggested that the mechanism of starch degradation in leaf sheaths could be different from that in germinating seeds.

In addition to starch degradation, sugar loading into phloem for transport to other storage organs also plays an important role in source tissues. The activation of the Arabidopsis sucrose transporter, AtSUC2, was considered a marker for the sink-source transition in leaves (Wright et al. 2003). During the sink-source transition in rice leaf sheaths, the mRNA levels of OSSUTI were found to be increased at the heading stage (Hirose et al. 1999). In our studies, expression of the set of OSSUT genes was identified during the sink-source transition of rice leaf sheaths. The results showed that not only expression of OSSUT1 but also of OsSUT4 was increased at the source stage (Fig. 4a, c), and it was suggested that these two OsSUTs could be responsible for sucrose loading into the phloem of source 


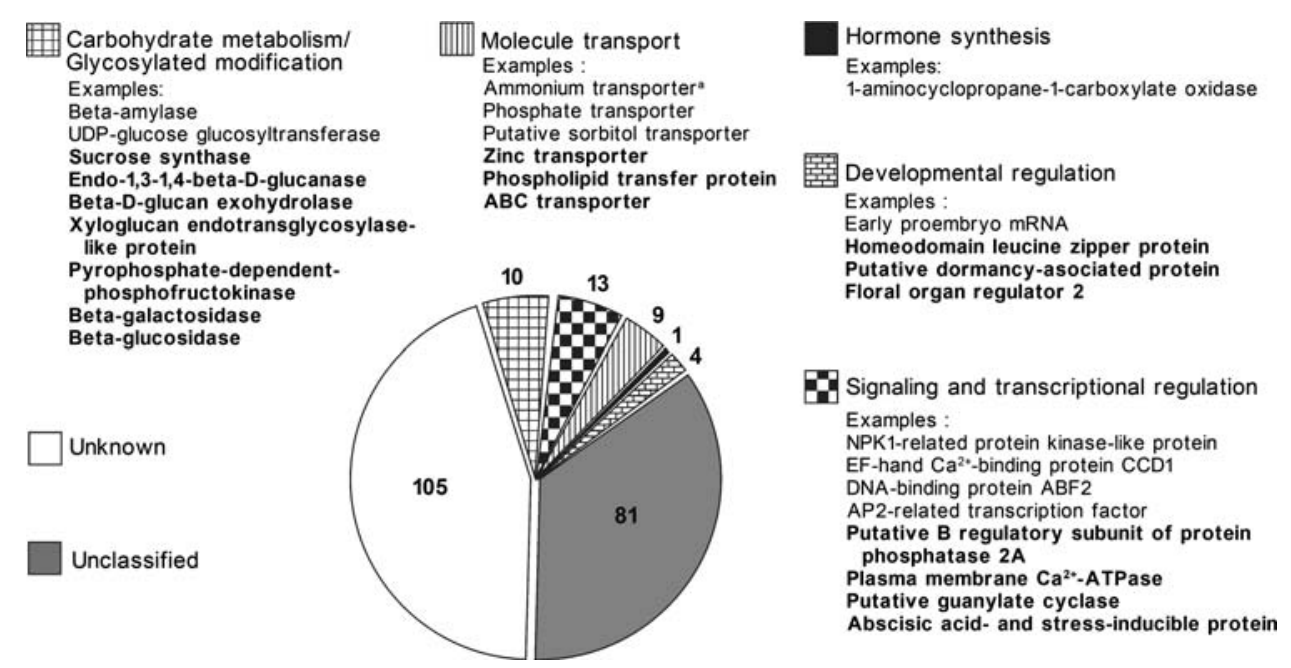

Fig. 5 Classification of the rice genes differentially expressed between the sink and the source leaf sheaths. The comparative transcriptome analysis revealed the differences in gene expressions between the sink and the source leaf sheath samples which were assessed by whole-genome microarray. A total of 223 genes showing at least threefold increased or repressed expressions in the source leaf sheaths compared with the sink samples were sorted into the various putative functional groups, and the number of genes classified in each functional group is indicated. The expression of carbohydrate

leaf sheaths. A similar OsSUT1 function was observed in the rice source leaves (Ishimaru et al. 2001; Scofield et al. 2002). Different expression patterns within the OsSUTs were also investigated in rice grains during the filling period (Aoki et al. 2003). In addition to the OSSUT genes, the expression of putative sorbitol transporter assessed by microarray and quantitative RT-PCR also changed significantly during the sink-source transition (Figs. 5, 7a). In some fruit species, sorbitol roles a primary photosynthetic product and a major phloem-translocated carbohydrate compound (Gao et al. 2003). However, less information was provided to elucidate the function of sorbitol in rice plants.

In this study, whole-genome expression profiling of leaf sheaths was also used to reveal the physiological and molecular mechanisms of the sink-source transition of leaf sheaths. Based on the microarray analysis, several genes related to carbohydrate metabolism, molecule transport, signal transduction/transcriptional regulation, hormone biosynthesis, and developmental regulation exhibited obviously differential expression in the leaf sheaths between the sink and the source stages (Fig. 5). Within the carbohydrate metabolism-related genes, sucrose synthase gene expression was positively correlated to starch content changes (Fig. 6a). According to a recent research, sucrose synthase functions to control ADP-glucose and transitory starch accumulation in leaves. In transgenic plants overexpressing sucrose synthase, both ADP-glucose and starch were highly increased in leaves (Muñoz et al. 2005). Here, metabolism-, glycosylated modification-, molecule transport-, hormone synthesis-, developmental regulation-, signaling- and transcriptional regulation-related genes listed here all have been further verified by real-time RT-PCR. The genes up-regulated in source leaf sheaths showed by regular font, and the genes downregulated after the leaf sheaths transited to source tissues were labeled with boldface font. Superscript ' $\mathrm{a}$ ' indicated the result of gene expression obtained from microarray was corrected by real-time RTPCR analysis

the increase in sucrose synthase expression at the preheading stage could be related to enhancing starch synthesis.

The mRNA levels of the other carbohydrate metabolism-related gene, $\beta$-D-glucan exohydrolase, were upregulated at the pre-heading and down-regulated at the post-heading stages (Fig. 6b). This enzyme was involved in cell wall loosening or degradation in germinating grains, elongating coleoptiles, and ripening fruits (Varghese et al. 1999; Lazan et al. 2004). The physiological functions of $\beta$-D-glucan exohydrolase in leaf sheaths still need further investigation.

During grain filling, the accumulation of nitrogen assimilates into developing grains is as important as that of starch compounds. In rice stems, nitrogen content was gradually increased after transplanting and peaked at flowering stage. Subsequently, the nitrogen content would be decreased after flowering (Ishizuka and Tanaka 1953). According to tracing with ${ }^{15} \mathrm{~N}$-labeled ammonium sulfate in rice plants, absorbed nitrogen in leaf blades and sheaths could be remobilized to growing organs during the reproductive stage (Mae and Ohira 1981). The major nitrogen source for rice plants growing in paddy fields is ammonium, and ammonium transporter expression in roots has been well studied in rice plants (Wang et al. 1993; Kumar et al. 2003; Sonoda et al. 2003). The expression of ammonium transporter has also been investigated in other tissues, such as leaves (Suenaga et al. 2003). As shown in Fig. $7 \mathrm{~b}$, transcript levels of ammonium transporter in the -2 


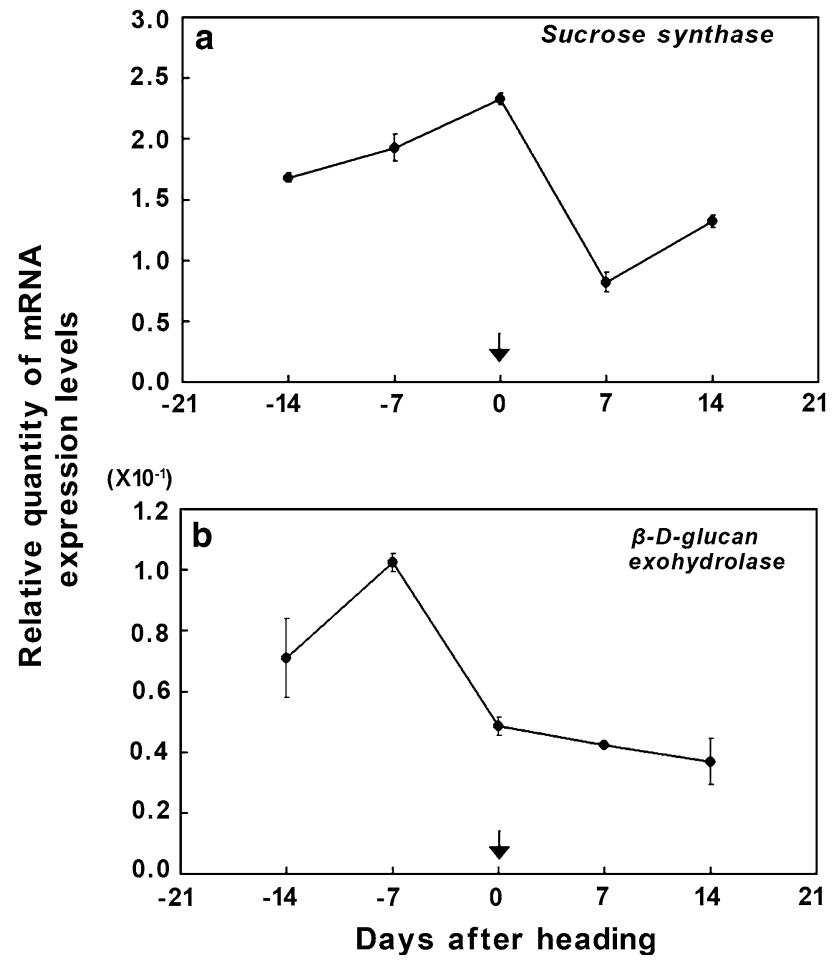

Fig. 6 Expression profiling of two selected carbohydrate metabolism-related genes in -2 leaf sheaths during the heading period. a Expressions of sucrose synthase gene. b Changes in the transcript levels of the $\beta$-D-glucan exohydrolase gene. The -2 leaf sheaths samples were collected at $-14,-7,0,7$ and 14 days after heading, and the gene expressions were determined by real-time RT-PCR. The data present the mean $\pm \mathrm{SE}$ of expression levels in three independent samples, and the standard errors are indicated with vertical bars. Arrows indicate the day of heading

leaf sheaths were strongly increased at 14 days after heading. Even though more evidence is needed addressing ammonium transporter functions in rice leaf sheaths during heading, the data obtained here suggest not only carbohydrate but also nitrogen source remobilization would be associated with the process of sink-source transition.

The phosphate transporter is essential for inorganic phosphate $\left(\mathrm{P}_{\mathrm{i}}\right)$ uptake from soil and $\mathrm{P}_{\mathrm{i}}$ redistribution in plants (Smith et al. 2003). Phosphate transporter expression increased at the post-heading period (Fig. 7c), implying that $\mathrm{P}_{\mathrm{i}}$ remobilization could be an active process in the source leaf sheaths. This finding is in concordance with observations on Pi content changes in rice leaf sheaths during the heading period (Tanaka 1961).

On the other hand, the other microarray analysis on the 1 leaf sheath of Nipponbare rice showed that the expression levels of several cell division and expansion-related genes were significantly different between the samples harvested at pre-heading and post-heading stages (Takahashi et al. 2005). However, those genes were not found in our result because the -2 leaf sheath of Tainung 67 rice was a fully
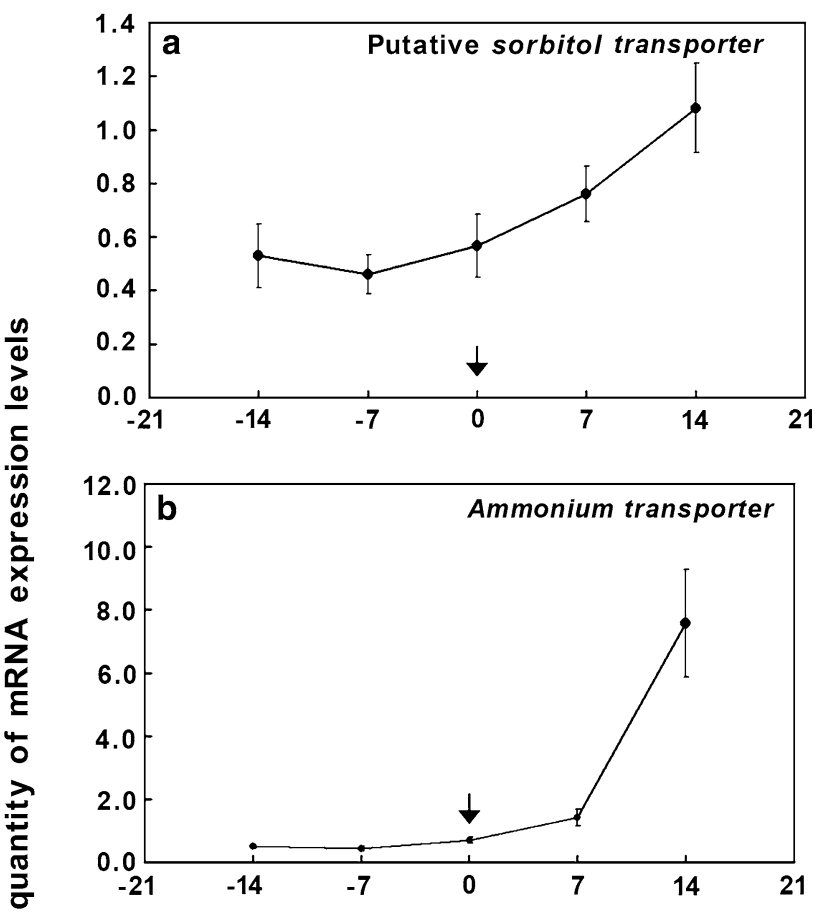

$\left(\times 10^{-1}\right)$

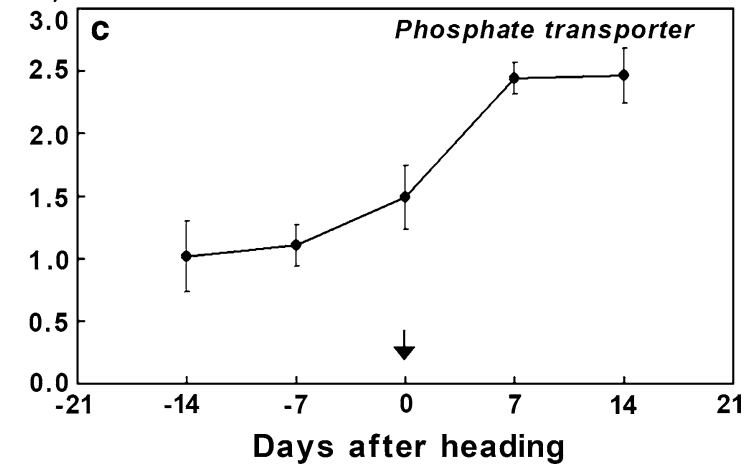

Fig. 7 Expression profiling of three selected molecule transportrelated genes in -2 leaf sheaths during the heading period. The -2 leaf sheaths samples were collected at $-14,-7,0,7$ and 14 days after heading, and the expressions of putative sorbitol transporter (a), ammonium transporter (b) and phosphate transporter genes (c) were determined by real-time RT-PCR. The data present the mean $\pm \mathrm{SE}$ of expression levels in three independent samples, and the standard errors are indicated with vertical bars. Arrows indicate the day of heading

expanded tissue during the sampling time of our experiments.

In conclusion, panicle exsertion is an important signal in the functional change of -2 leaf sheaths from sink to source during the heading period. AGP-L2, GBSSII, SSSI, SBEI, SBEIII, SBEIV, sucrose synthase, and $\beta$-amylase were the major genes controlling starch metabolism in the -2 leaf sheaths during the heading period. OsSUT1, OsSUT4, and the putative sorbitol transporter could function to remobilize carbohydrate from leaf sheaths to the sink tissues during grain filling. In addition to OsSUTs, the ammonium 
transporter and the phosphate transporter might also play important roles in nutrition translocation in source leaf sheaths. Expression of these genes could serve as molecular markers of the sink-source transition in rice leaf sheaths. In future, investigations of regulatory mechanism on starch metabolism and nutrient transport in leaf sheaths during the heading period would be helpful to increase our understanding of the regulatory mechanisms of the sinksource transition.

Acknowledgments We thank Dr. L.F. Liu and Dr. H. S. Lur (National Taiwan University, Taipei, Taiwan) for their helpful comments and discussions. This research was supported by the National Science Council, Taiwan.

\section{References}

Akihiro T, Mizuno K, Fujimura T (2005) Gene expression of ADPglucose pyrophosphorylase and starch contents in rice cultured cells are cooperatively regulated by sucrose and ABA. Plant Cell Physiol 46:937-946

Aoki N, Scofield GN, Wang XD, Patrick JW, Offler CE, Furbank RT (2003) The sucrose transporter gene family in rice. Plant Cell Physiol 44:223-232

Blum A, Sinmena B, Mayer J, Golan G, Shpiler L (1994) Stem reserve mobilization supports wheat-grain filling under heat stress. Aust J Plant Physiol 21:771-781

Chu C, Lee TM (1989) The relationship between ethylene biosynthesis and chilling tolerance in seedlings of rice (Oryza sativa L.). Bot Bull Acad Sinica 30:263-273

Cock JH, Yoshida S (1972) Accumulation of ${ }^{14}$ C-labelled carbohydrate before flowing and its subsequent redistribution and respiration in the rice plant. Proc Crop Sci Soc Jpn 41:226-234

Déjardin A, Sokolov LN, Kleczkowski LA (1999) Sugar/osmoticum levels modulate differential abscisic acid-independent expression of two stress-responsive sucrose synthase genes in Arabidopsis. Biochem J 344:503-509

Dian W, Jiang H, Wu P (2005) Evolution and expression analysis of starch synthase III and IV in rice. J Exp Bot 56:623-632

Dingkuhn M, Schnier HF, De Datta SK, Dorffling K, Javellana C (1991) Relationship between ripening-phase productivity and crop duration, canopy photosynthesis and senescence in transplanted and direct-seeded lowland rice. Field Crops Res 26:327345

Gao Z, Maurousset L, Lemoine R, Yoo SD, Nocker S, Loescher W (2003) Cloning, expression, and characterization of sorbitol transporters from developing sour cherry fruit and leaf sink tissues. Plant Physiol 131:1-10

Hirose T, Terao T (2004) A comprehensive expression analysis of the starch synthase gene family in rice (Oryza sativa L.). Planta 220:9-16

Hirose T, Endler A, Ohsugi R (1999) Gene expression of enzymes for starch and sucrose metabolism and transport in leaf sheaths of rice (Oryza sativa L.) during the heading period in relation to the sink to source transition. Plant Prod Sci 2:178-183

Hirose T, Ohdan T, Nakamura Y, Terao T (2006) Expression profiling of genes related to starch synthesis in rice leaf sheaths during the heading period. Physiol Plant 128:425-435

Ishikawa T, Akita S, Li Q (1993) Relationship between contents of non-structural carbohydrates before panicle initiation stage and grain yield in rice (Oryza sativa L.). Jpn J Crop Sci 62:130-131
Ishimaru K, Hirose T, Aoki N, Takahashi S, Ono K, Yamamoto S, Wu J, Saji S, Baba T, Ugaki M, Matsumotoi T, Ohsugi R (2001) Antisense expression of a rice sucrose transporter OsSUT1 in rice (Oryza sativa L.). Plant Cell Physiol 42:1181-1185

Ishimaru K, Kosone M, Sasaki H, Kashiwagi T. (2004) Leaf contents differ depending on the position in a rice leaf sheath during sinksource transition. Plant Physiol Biochem 42:855-860

Ishizuka Y, Tanaka A (1953) Biochemical studies on the life history of rice plants I. Absorption and translocation of inorganic elements. J Sci Soil Manure Jpn 23:23-28

Karrer EE, Rodriguez RL (1992) Metabolic regulation of rice $a$ amylase and sucrose synthase gene in planta. Plant J 2:517-523

Keppler D, Decker K (1974) Glycogen: determination with amyloglucosidase. In: Bergmeyer HU (ed) Methods of enzymatic analysis, vol 3. Academic Press, New York, pp 1127-1131

Kumar A, Silim SN, Okamoto M, Siddiqi MY, Glass AD (2003) Differential expression of three members of the AMT1 gene family encoding putative high-affinity $\mathrm{NH}_{4}{ }^{+}$transporters in roots of Oryza sativa subspecies indica. Plant Cell Environ 26:907914

Lazan H, Ng SY, Goh LY, Ali ZM (2004) Papaya beta-galactosidase/ galactanase isoforms in differential cell wall hydrolysis and fruit softening during ripening. Plant Physiol Biochem 42:847-853

Mae T, Ohira K (1981) The remobilization of nitrogen related to leaf growth and senescence in rice plants (Oryza sativa L.) Plant Cell Physiol 22:1067-1074

Mizuno K, Kawasaki T, Shimada H, Satoh H, Kobayashi E, Okumura S, Arai Y, Baba T (1993) Alteration of the structural properties of starch components by the lack of an isoform of starch branching enzyme in rice seeds. J Biol Chem 268:19084-19091

Muñoz FJ, Baroja-Fernandez E, Moran-Zorzano MT, Viale AM, Etxeberria E, Alonso-Casajus N, Pozueta-Romero J (2005) Sucrose synthase controls both intracellular ADP glucose levels and transitory starch biosynthesis in source leaves. Plant Cell Physiol 46:1366-1376

Nakano H, Makino A, Mae T (1995) Effects of panicle removal on the photosynthetic characteristics of the flag leaf of rice plants during the ripening stage. Plant Cell Physiol 36:653-659

Nakamura Y, Takeichi T, Kawaguchi K, Yamanouchi H (1992) Purification of two forms of starch branching enzyme (Qenzyme) from developing rice endosperm. Physiol Plant 84:329335

Ohdan T, Francisco PB, Sawada T, Hirose T, Terao T, Satoh H, Nakamura $Y$ (2005) Expression profiling of genes involved in starch synthesis in sink and source organs of rice. J Exp Bot 56:3229-3244

Perez CM, Palmiano EP, Baun LC, Juliano BO (1971) Starch metabolism in the leaf sheaths and culm of rice. Plant Physiol 47:404-408

Samonte SOPB, Wilson LT, McClung AM, Tarpley L (2001) Seasonal dynamics of nonstructural carbohydrate partitioning in fifteen diverse rice (Oryza sativa L.) genotypes. Crop Sci 41:902-909

Scofield GN, Hirose T, Gaudron JA, Upadhyaya NM, Ohsugi R, Furbank RT (2002) Antisense suppression of the rice sucrose transporter gene, OsSUT1, leads to impaired grain filling and germination but does not affect photosynthesis. Funct Plant Biol 29:815-826

Smith FW, Mudge SR, Rae AL, Glassop D (2003) Phosphate transport in plants. Plant Soil 248:71-83

Smith AM, Zeeman SC, Smith SM (2005) Starch degradation. Annu Rev Plant Biol 56:73-98

Sokolov LN, Déjardin A, Kleczkowski LA (1998) Sugars and light/ dark exposure trigger differential regulation of ADP-glucose pyrophosphorylase genes in Arabidopsis thaliana (thale cress) Biochem J 336:681-687 
Sonoda Y, Ikeda A, Saiki S, Yamaya T, Yamaguchi J (2003) Feedback regulation of the ammonium transporter gene family AMT1 by glutamine in rice. Plant Cell Physiol 44:1396-1402

Suenaga A, Moriya K, Sonoda Y, Ikeda A, Von Wiren N, Hayakawa T, Yamaguchi J, Yamaya T (2003) Constitutive expression of a novel-type ammonium transporter OsAMT2 in rice plants. Plant Cell Physiol 44:206-211

Takahashi S, Ishimaru K, Yazaki J, Fujii F, Shimbo K, Yamamoto K, Sakata K, Sasaki T, Kishimoto N, Kikuchi S (2005) Microarray analysis of sink-source transition in rice leaf sheaths. Breed Sci 55:153-162

Tanaka A (1961) Studies on the nutrio-physiology of leaves of rice. Plant. J Fac Agric Hokkaido Univ 51:449-550

Tetlow IJ, Morell MK, Emes MJ (2004) Recent developments in understanding the regulation of starch metabolism in higher plants. J Exp Bot 55:2131-2145

Thomas BR, Rodriguez RL (1994) Metabolite signals regulate gene expression and source/sink relations in cereal seedlings. Plant Physiol 106:1235-1239

Varghese JN, Hrmova M, Fincher GB (1999) Three-dimensional structure of a barley $\beta$-D-glucan exohydrolase, a family 3 glycosyl hydrolase. Structure 7:179-190
Wang MY, Siddiqi MY, Ruth TJ, Glass ADM (1993) Ammonium uptake by rice roots. II. Kinetics of ${ }^{13} \mathrm{NH}_{4}{ }^{+}$influx across the plasmalemma. Plant Physiol 103:1259-1267

Watanabe Y, Nakamura Y, Ishii R (1997) Relationship between starch accumulation and activities of the related enzymes in the leaf sheath as a temporary sink organ in rice (Oryza sativa). Aust J Plant Physiol 24:563-569

Wright KM, Roberts AG, Martens HJ, Sauer N, Oparka KJ (2003) Structural and functional vein maturation in developing tobacco leaves in relation to AtSUC2 promoter activity. Plant Physiol 131:1555-1565

Yang J, Zhang J, Wang Z, Xu G, Zhu Q (2004) Activities of key enzymes in sucrose-to-starch conversion in wheat grains subjected to water deficit during grain filling. Plant Physiol 135:1621-1629

Yoshida S (1972) Physiological aspects of grain yield. Annu Rev Plant Physiol 3:437-464 